\title{
Psychiatry in Contemporary Iran: A Survey of Views and Practices of a Group of Iranian Psychiatrists
}

A. H. Mehryar, Department of Psychology, Shiraz University, Shiraz, Iran. (Currently on leave at the Center for Cognitive Therapy, University of Pennsylvania, Philadelphia, USA); M. R. MuHARreri, Ministry of Health, Shiraz, Iran, K. NourI, Boston University, Boston, Massachusetts, USA, and F. KhAJAvI,* Medical Arts Building, New England Memorial Hospital, Stoneham, Massachusetts 02180, USA

(*correspondence)

Psychiatry has a long past but a short history in Iran. References to causes and treatment of mental disorders can be found in parts of the Avesta, the holy book of pre-Islamic Iranians. Early muslim physicians like Tabari, Majusi, Razi and Ibn Sina, who were mostly born and brought up in Iran, have devoted long sections of their books to a discussion of mental disorders under the general title of 'the diseases of the head and the brain'. In fact, the oldest medical textbook in modern Persian-which was completed around 970 A.D. - was written by a practising physician who claims to have been known as a 'doctor of the insane' by his contemporaries.

Western psychiatry, like the rest of modern medicine, was introduced to Iran in late 19th century by European doctors teaching at the then newly established Tehran Medical School. The first Iranian doctors with specialised training in neuropsychiatry returned from France in the 1930s and helped to establish an independent teaching department and a few mental health facilities in Tehran. After the war, many more Iranian doctors received postgraduate training in psychiatry in the UK and the USA. By the late 1970s there were some seven psychiatry departments in Tehran and other provincial university centers and the Iranian Psychiatric Association claimed some 300 registered members.

The aim of this study was to get a quantitative picture of the profession as it entered the 1980s. Drastic changes had taken place in Iranian society and psychiatry, more than any other branch of medicine, was being asked to adapt itself to the new beliefs and values ushered in by the Islamic Revolution. A small stock-taking at this critical period seemed necessary for later evaluations of the impact of the Revolution on Iranian psychiatry. To this end, a questionnaire was mailed to a group of 120 Iranian psychiatrists (about $50 \%$ of those listed in the membership register of the Iranian Psychiatric Association). Fifty-four of the questionnaires were returned in due course to be included in this report.

\section{Findings}

The main socio-demographic and professional characteristics of the respondents are as follows: $92.5 \%$ male; over $70 \%$ located in Tehran and the rest in other major provincial centres; almost $65 \%$ are employed by the Ministry of Health, another $22 \%$ by universities; $78 \%$ have admitted to having a private practice; $89 \%$ have completed postgraduate training or Board in psychiatry, $27 \%$ of them in Europe or the USA. In terms of the area of specialisation, $68 \%$ have defined their field of specialisation as general (adult) psychiatry, 15\% as general plus child and adolescent psychiatry, $13 \%$ as general psychiatry and neurology. Only one respondent has claimed specialisation in a combination of general and geriatric psychiatry. Most of the respondents have said that they are entirely $(68 \%)$ or somewhat $(26 \%)$ satisfied with their chosen field of specialisation and service.

Patient load and characteristics: from responses given by 42 of the respondents, the amount of weekly clinical work or patient contact undertaken would seem to vary from 10 hours to over 50 hours, the average being 32 hours. Similarly, the number of patients seen in a typical week would seem to vary from less than 20 to over 340 cases, the overall average being 83 . The majority of patients seen are defined as female by about $50 \%$ of respondents, a preponderance of male patients being reported by only $12 \%$. With regard to the age of their clients, the largest number (30) of respondents have maintained that most of their patients are aged between 25 and 35 years, another seven giving the 15 to 25 years age group. Only five have mentioned that most of their clients are aged above 35 years. With respect to the social class of their clients, the majority (26) of respondents claim that most of their patients come from middle-middle class backgrounds. Lower-middle and lower class patients have been claimed by 15 and six respondents, respectively. Only three respondents maintained that most of their clients come from upper-middle or higher classes.

Diagnostic groups of clients: To obtain a measure of the occurrence of various psychiatric disorders among the clients of Iranian psychiatrists, respondents had been asked to rank different disorders according to their frequency of occurrence. The mean of the rankings received by each disorder will be used as a measure of its relative occurrence. Note that the higher the mean, the more common the disorder in question. Using this index, the relative occurrence of the nine general diagnostic categories is as follows: Neurotics in general (8.02), psychosomatic disorders (7.18), functional psychoses as a group (6.49), family and marital problems (5.39), personality disorders (4.76), organic 
disorders and mental retardation (4.56), childhood behaviour problems (3.60), drug addiction (3.10), and other physical illnesses (2.47). Within the neurotic group, the relative occurrence of the five major diagnostic groups are found to be as follows: anxiety reaction (5.46), reactive or neurotic depression (5.26), obsessive-compulsive disorder (3.18), mild or neurotic post-partum reactions (1.97), phobic disorder (1.49), and hysterical reaction (1.19). In the case of the seven psychotic diagnostic categories used the relative ranks are found to be: schizophrenia (6.49), manicdepressive illness (5.27), psychotic depression (4.85), paranoia (3.69), organic psychoses (3.41), post-partum psychoses (3.18), and other toxic-drug induced psychoses (1.59).

Clinical Practices

Drug therapy is the main mode of treatment mentioned. The list of drugs cited covers the whole gamut of psychotropic preparations available in the West. Iranian physicians are usually expected to prescribe several drugs simultaneously. A government decision to restrict prescriptions to a standard list of generic preparations proposed by the Ministry of Health has led to much criticism on the part of patients and doctors.

Electroconvulsive treatment is also known to be widely used, but only 18 of the respondents have bothered to specify the number of patients they treat by ECT in a typical week. The numbers given vary from 1 to 25 cases, the average being 5.8. The number of ECTs given to each patient, as reported by 37 respondents, varies from 4 to $9+$, the average being 7.5. However, over one half of the respondents have reported $8+$ and over one third have reported $9+$ ECTs. Of the 42 respondents who have specified the mode of giving ECT, the majority claim that it is always administered bilaterally $(88 \%)$ and under general anaesthesia $(76 \%)$. The most frequently mentioned indications for ECT are catatonic schizophrenia (28), endogenous depression (11), post-partum psychoses (10), psychotic depression (9), manic states (8), depression in general (8), schizophrenia not responding to drugs (8), involutional depression or melancholia (7), manic-depressive illness (6), suicidal patients (6), and acute paranoid schizophrenia (6).

Psychotherapy. Only four of the respondents have claimed the regular use of psychotherapy in the exact and systematic sense of the word. Another 28 respondents have reported frequent use of psychotherapy. With regard to the type of psychotherapy used, the large majority have mentioned individual psychotherapy, an exclusive use of group therapy being reported by only one respondent. In terms of school or theoretical orientation of psychotherapy, the respondents distribute as follows: psychoanalytic, 19; eclectic, 17; neo-Freudian, religious, transactional analysis, and psychobiology, one respondent each! Psychotherapy sessions are reported to take from 15 to 60 minutes, with $62 \%$ mentioning 45 minutes or more per session. The main indications for psychotherapy are given as follows: neurosis in general (35); marital-sexual problems (6); neurotic depression (5); neurotic anxiety (5); and psychosis (3). Of the various methods of psychotherapy, supportive psychotherapy has been singled out by the largest number of respondents (16) as the most applicable in the Iranian cultural setting. Insight-analytic and individual psychotherapy come next, each endorsed by six respondents only. The largest number of respondents (34) have claimed that among Iranian patients neurotics respond best to psychotherapy. A smaller number have mentioned 'educated people' as best responding to psychotherapy.

\section{Causes of mental illness in Iran}

Using a 22-item close-ended format, it was found that, in the opinion of the psychiatrists surveyed, the most probable social determinants of mental illness in contemporary Iran are as follows: unemployment and job insecurity (mentioned by 41 respondents), poverty, malnutrition and ill-health (36), loss of national identity and culture (32), disappearance of the traditional extended family (27), political dictatorship and abuse of power by past governments, an increase in divorce rate, and rapid urbanisation (mentioned by 26 respondents each). Moreover, most of the respondents (46) have claimed that they have noticed an increase in the rate of mental disorders over the preceding few years. Disorders that are believed to have increased are, in descending order, anxiety reaction, neurotic depression, irritability and aggressiveness, psychosomatic disturbances, family problems, severe affective disturbances, drug addiction, social deviance and crime, and severe psychotic reactions such as schizophrenia. Thirty-eight of the respondents also indicated that they noticed a change in the socio-economic composition of their clients over the past few years.

In connection with the presumed increase in the incidence of psychiatric disorders over the past few years, the following groups are mentioned as the main casualties: young people (44), women (40), the inhabitants of Tehran and other large cities (38), the middle-aged population (30), and men (27). A large number of respondents (38) have also claimed that their own clinical practice has been adversely affected by the upheaval of the past few years. The main reasons given for this negative impact are scarcity of drugs (29), increase of patients (18), lack of hospital facilities (16), heightened expectations of clients (12), lowering of physicians' fees by the authorities (11), personal loss of interest (9), loss of morale (7), and deficiencies in laboratory facilities.

With regard to the future development of mental health services and manpower, the majority (44) of respondents have indicated that priority should be given to training general practitioners in the diagnosis and the primary care of psychiatric patients. The training of more psychiatrists (30), psychiatric nurses (25), psychiatric social workers (23), psychiatric nurses' aides (21), and psychologists (20) is also recommended. Among the mental health facilities believed to be of priority importance are psychiatric wards associated with general hospitals (32), community mental health clinics linked with a hospital (31), child guidance clinics (25), comprehensive psychiatric centres (24), mental hospitals (18) and day hospitals (15). 
Discussion

The picture of Iranian psychiatry revealed by this survey is of a modern profession very much influenced by western psychiatry. This is not unexpected given the western training of people responsible for the development of modern psychiatry in Iran. There is little evidence that the ideological furore unleashed by the Islamic Revolution has so far affected the views and practices of Iranian psychiatrists. Periodic exhortations to Islamicise psychiatry and other health professions have usually had to be abandoned because of the absence of a clearly defined alternative. The main impact of anti-western campaigns in universities has been to force more physicians to leave the country or to go into private practice in Tehran.

The results of this survey also indicate that the overwhelming majority of Iranian psychiatrists are located in Tehran and a few other major urban centres which can account for no more than $\mathbf{4 0 \%}$ of the population of Iran. The main beneficiaries of the existing psychiatric resources appear to be urban middle-class people, mostly young women. The picture is supported by the official statistics collected by the Iranian Medical Association. According to these statistics, in 1981, there were 295 registered specialists in psychiatry and neurology. Of these $71 \%$ were listed as working in Tehran ${ }^{1}$. Thus, not only the number of trained neuropsychiatrists per million of population (about 7.6) was lower than those reported for some other developing countries $^{2.3 .4}$ but also the geographic distribution of the existing manpower was extremely biased in favour of Tehran. While the ratio of neuropsychiatrist per million of population was close to 32 in Tehran it was only six in Fars province which has the second highest ratio. In fact eight of the 23 provinces of the country with a total population of six million had no trained neuropsychiatrists at all. In the face of these glaring inequalities in access to existing services, the only successful scheme enforced by Government has been to require all physicians working in Tehran and other major cities to spend one month per year in a disadvantaged area of the country. The impact of such an emergency measure on a medical speciality like psychiatry, which requires close interpersonal involvement and continuity of care, remains to be established.

REFERENCES

'Statistical Center of Iran (1982) Statistical Yearbook for the Year 1360 (1980-1981). Tehran: Statistical Center of Iran (In Persian).

${ }^{2}$ BAASHER, T. A. (1976) Mental health services in Eastern Mediteranean countries. World Health Organization Chronicle. 30, 234-239.

${ }^{3}$ Neki, J. S. (1973) Psychiatry in South-East Asia. British Journal of Psychiatry, 123, 257-269.

${ }^{4}$ Leon, C. A. (1972) Psychiatry in Latin America. British Journal of Psychiatry, 121, 121-136.

\section{PRIME}

PRIME (Psychological Research in Industry, Medicine and Education), a new charity, was founded by the Society of Clinical Psychiatrists, and seeks to examine new approaches in some of the most widespread causes of suffering faced by individuals, their families and the health service. It aims to draw together eminent workers in medical sciences, psychiatry and psychology to pool their expertise and build bridges between disciplines which too often work in isolation and to bring them into co-operation with volunteers, some of whom have first-hand experience of the current psychiatric services. Further information: Dr Alick Elithorn, Honorary Secretary, PRIME, 1 Constantine Road, Hampstead, London NW3 (telephone 01482 5677).

\section{The Obsessive Compulsive Neurosis Support Group}

This group aims to act as a support and self-help system for sufferers of this illness, family, friends and caring people in the community, and to increase public awareness and understanding through media articles and seminars. Further information: Colin Slocombe, OCNSG (Inc), 33 Pirie Street, Adelaide 5000, Australia.

\section{Resource Network for Disordered Adolescents}

This Network has been set up to promote co-operation and enhance competency among agencies in providing high standards of service for disordered adolescents with problems including substance abuse, unemployment, impact of family break-up and adolescent homelessness, self-injury, rising crime and custody rates in this age group, as well as a wide range of both general and specific psychological and psychiatric disorders. Further information: Dr Masud Hoghughi, Aycliffe School, Copelaw, Newton Aycliffe, Co. Durham DL56JB.

\section{Anorexia Nervosa and Obsessive- compulsive Disorder in Young Children}

The Hospitals for Sick Children are currently attempting to collect a series of young children with anorexia nervosa and another series with obsessive-compulsive disorder. They would be happy to receive referrals of any children with either by these disorders aged 14 or under. Please contact Dr Bryan Lask, Consultant Psychiatrist, The Hospitals for Sick Children, Great Ormond Street, London WCIN 3JH (telephone 01405 9200). 